\title{
Migrations: Interdisciplinary Perspectives
}

\author{
edited by Michi Messer, Renee Schroeder, and Ruth Wodak \\ Vienna: Springer-Verlag 2012 \\ ISBN 978-3-7091-0949-6 \\ Hardcover, \$209, 358 pp.
}

\author{
Reviewed by Sharon M. Lee \\ University of Victoria
}

This edited volume is based on invited papers presented by "prominent international researchers from the humanities, social sciences and natural sciences" (Preface: vi) at a three-day conference on "Migrations: Interdisciplinary Perspectives" held at the University Campus of Vienna from July 1 to 3, 2010. The conference is one of a series of events supported and/or organized by the University of Vienna's Forum for Interdisciplinary Dialogue (IDee).

The 358-page volume begins with a preface by the three editors (pp. v to xiii). They describe the background for the conference and edited volume, and discuss the complex "threefold challenge" in organizing the conference: (i) the meanings and methods of interdisciplinary research, (ii) the complexity of migration and how to study it, and (iii) "the complex (socio-/geo-) political dimensions associated with migrations and the (all too) often unvoiced presuppositions."

The main body of the volume consists of the papers presented at the conference. The papers are grouped into eight parts and themes. Part I, Interdisciplinary Approaches: Theories and Methodologies, has four papers. There are five papers in Part II, Peer Relations among Immigrant Adolescents: Methodological Challenges and Key Findings. Part III, Migration, Identity, and Belonging, and Part IV, Ego Documents Entered Migration History, each has a brief introduction followed by three papers. Part V, Debating Migrations, has five papers. There are two papers in Part VI, Diffusion and Spread in the Natural Sciences and Beyond. Part VII, Media Representations of Migrants and Migration, has a brief introduction, followed by two papers. The final part, Part VIII, Migration and the Genes, also has two papers, preceded by an introduction. Brief biographies of the editors and contributors are on pages 341-352, and the volume concludes with an index.

Reviewing an edited volume poses distinct challenges compared to reviewing a book written by one or more authors on a particular subject. First, there is the wide range of specific topics included, even though they are intended to relate to migration. In this volume, the papers address peer relations among migrant youths, bullying and victimization in ethnically diverse schools, identity and belonging issues, the role of the media in perpetuating racism and anti-migrant attitudes, "barbarians" and the fall of the Roman Empire, and discourse analysis of the "parasite" and "fluidity" metaphors when used with reference to migration (for example, "migrants first trickle in, then turn into streams and at last flood a peaceful country;" p. 206).

Related to the first challenge is a second challenge, where contributors use different data, theoretical perspectives, and methodologies. Thus, there are contributions from a wide range of scholars, including psychologists, historians, anthropologists, linguists, physicists, geneticists, botanists, and several others from fields such as communication, discourse, intercultural studies, and transnational studies. The latter fields usually try to bridge multiple disciplines, but most of the scholars from these fields appear to be from the humanities.

A third challenge of this volume is its historical and geographical diversity. For example, there is a paper on migration in ancient Egypt by an Egyptologist; a paper by a historian that examines immigrant love letters 
written during the 1940s between two lovers_-one in Canada, the other back in Italy; a contemporary analysis by a discourse scholar of the role of the media and racism; and several quantitative studies by psychologists and linguists of immigrant youths in various European countries today.

A final challenge (which is related to the second challenge described above) is the fact that most contributors write from a disciplinary approach, using that discipline's language, data, and methodologies. To truly do justice in a review of this volume, one would have to solicit reviews of different chapters by different reviewers, for example, a psychologist and linguist for the paper on multilingualism and linguistic integration of migrants, an Egyptologist for the paper on migration in ancient Egypt, a transnationalism scholar for the paper on Vietnamese refugees in Ireland, and a geneticist for the papers on migration and genes. A particularly interesting example of what this implies is represented by the paper on the spread of ragweed as a diffusion process by four co-authors whose backgrounds are in physics, vegetation science, and ecology — a paper quite beyond the scope of this sociologist and demographer.

This last challenge means that in spite of its intention to address migration from interdisciplinary perspectives, this edited volume consists of papers, each written by author(s) from a particular discipline using that discipline's theoretical perspectives, data, and methodology. A reader searching for a particular paper on a particular topic from a particular discipline is more likely to be successful than a reader looking for interdisciplinary research or discussions of migration-related topics. Thus, a more accurate title of the volume would be Multiple Perspectives on Migrations.

The editors' intention to “deconstruct the complex phenomenon of migration(s) from as many perspectives as possible" and to "bridge many gaps: between disciplines and faculties, between politics and science, between experts and the general public, and between migrants themselves and individuals or organizations fighting for the human rights and dignity of migrants, on the one hand, and policymakers and bureaucrats who take the decisions, on the other hand" (Preface: xi-xii) is laudable. The volume succeeds in including many perspectives on migration, but falls short in the goal of bridging the different gaps. Many people worked extremely hard to organize the conference and publish this volume. However-except for the five excellent papers in Part II addressing different issues related to immigrant youths (including the study by Elisabeth Stefanek, Dagmar Strohmeier, Rens van de Schoot, and Christiane Spiel on the role of ethnicity and ethnic diversity on bullying and victimization, with its surprising results); the paper by Janine Dahinden in Part III, which uses three case studies of migrants in Switzerland (a highly-skilled female migrant born in Egypt but with UK citizenship, a low-skilled temporary worker from Albania, and a Ukrainian cabaret dancer) to encourage rethinking trans-nationalism and the meaning of migrant integration; and Majid Khosravinik, Michal Krzyanowski, and Ruth Wodak's paper in Part VII on how immigrants are represented in the British press-readers of Canadian Studies in Population and other migration researchers will not be missing much if they do not have access to this volume. 